\title{
Influence of Synthesis Conditions on the Physicochemical Properties and Catalytic Activity of Fe/Cr-Pillared Bentonites
}

\author{
Fatma Tomul \\ Department of Science Education, Education Faculty, Mehmet Akif Ersoy University, 15100 Burdur, Turkey \\ Correspondence should be addressed to Fatma Tomul, tomulf@gmail.com
}

Received 13 September 2011; Accepted 7 October 2011

Academic Editor: Anukorn Phuruangrat

Copyright () 2012 Fatma Tomul. This is an open access article distributed under the Creative Commons Attribution License, which permits unrestricted use, distribution, and reproduction in any medium, provided the original work is properly cited.

The synthesis of Fe/Cr-pillared bentonites starting from a $2 \%$ clay suspension and also from dry clay using ultrasound treatment for both the aging and the intercalation steps of the pillaring solution considerably reduces the time and the amount of water required compared with the conventional synthesis method. The catalysts were characterized using scanning electron microscopy with an energy dispersive system (SEM-EDS), powder X-ray diffraction (XRD), $\mathrm{N}_{2}$ and $\mathrm{CO}_{2}$-adsorption/desorption, electron paramagnetic resonance (EPR), Fourier-transform infrared spectroscopy (FTIR) and thermogravimetric (TG) analysis and the catalytic activity of selected samples was evaluated for the phenol oxidation reaction. The results of XRD analysis showed that delaminated Fe/Cr-pillared bentonite with $\mathrm{d}_{001}$ value $68 \AA$ was observed after intercalation a direct mixture of the pillaring solution and dry clay. The adsorption-desorption isotherm analysis showed that the samples synthesized with the proposed methodology in intercalation stage have similar textural properties and these properties do not change remarkably with synthesis conditions. In addition, the characterisation studies showed that the physicochemical properties of samples synthesized by ultrasound were comparable to those of sample synthesized by conventional method in this study. The sample synthesized by conventional method show $50 \%$ phenol conversion. This value was higher than those of samples synthesized by the ultrasound.

\section{Introduction}

Pillared clays have been studied as potential micro/mesoporous materials for use as catalysts and catalyst supports on the industrial scale because of their well-controlled pore structure and catalytic properties [1-4]. However, the excessive amount of water required for the diluted clay suspensions and pillaring agents, combined with long synthesis times for the pillared clays, makes it difficult to produce them on the industrial scale $[5,6]$. For this reason, studies related to developing a more rapid synthesis of these materials have recently become important. At this point in the development of pillared clay catalysts for the industrial scale, it is important to improve their physicochemical and catalytic properties as well as to develop synthesis methods that decrease their production time and water use [6-10].

The literature indicates that catalysts that include chromium and/or iron give good results for reactions such as methanol dehydration [11], ethylbenzene dehydrogenation
[12], Fischer Tropsch synthesis [13], aromatic nitration, the toluene disproportionation [14], carbon monoxide oxidation $[15,16]$, catalytic acylation of alcohols [17], and phenol oxidation $[6,18-21]$.

In the literature, the studies related to iron/chromiummixed pillared clay are especially limited in number, even though it is well known that these metals provide superior results for various catalytic reactions. Chromium is preferable for catalytic applications because of its large range of oxidation numbers despite the major disadvantage that the pillared structure of the chromium-pillared clays is damaged when calcined at high temperatures, decreasing the surface area $[22,23]$. The disadvantage of Fe-pillared interlayered clays is the result of their small basal spacing, which could adversely impact their surface areas and pore properties and thus reduce their reaction activities [24]. Related studies have implied that catalytic activity can be increased by adding a second metal to the structure of the pillared clays produced using the iron pillaring solution [25]. 
TABle 1: Preparative conditions and nomenclature of the solids obtained.

\begin{tabular}{lccll}
\hline Nomenclature & Fe/Cr ratio & Fe/Fe + Cr ratio & Aging of pillaring solution & Intercalation \\
\hline Fe/Cr0.75 & $15: 5$ & 0.75 & $\begin{array}{l}\text { Fe/Cr pillaring solution aged for } 24 \mathrm{~h} \text { at } \\
\text { room temperature }\end{array}$ & $\begin{array}{l}\text { Fe/Cr pillaring solution slowly added to } \\
2 \% \text { bentonite suspension and aged for } \\
24 \mathrm{~h} \text { at room temperature }\end{array}$ \\
Fe/Cr0.75(D) & $15: 5$ & 0.75 & $\begin{array}{l}\text { Fe/Cr pillaring solution sonicated for } 30 \\
\text { minutes at } 35 \mathrm{~Hz} \text { and } 75^{\circ} \mathrm{C}\end{array}$ & $\begin{array}{l}\text { Dry clay directly added to Fe/Cr-pillaring } \\
\text { solution sonicated for } 30 \text { minutes at } 35 \mathrm{~Hz} \\
\text { and } 75^{\circ} \mathrm{C}\end{array}$ \\
Fe/Cr0.75(CS) & $15: 5$ & 0.75 & $\begin{array}{l}\text { Fe/Cr pillaring solution sonicated for } 30 \\
\text { minutes at } 35 \mathrm{~Hz} \text { and } 75^{\circ} \mathrm{C}\end{array}$ & $\begin{array}{l}\text { Dry clay slowly added to Fe/Cr-pillaring } \\
\text { solution sonicated for } 30 \text { minutes at } 35 \mathrm{~Hz} \\
\text { and } 75^{\circ} \mathrm{C}\end{array}$ \\
& $15: 5$ & 0.75 & $\begin{array}{l}\text { Fe/Cr pillaring solution sonicated for } 30 \\
\text { minutes at } 35 \mathrm{~Hz} \text { and } 75^{\circ} \mathrm{C}\end{array}$ & $\begin{array}{l}\text { Fe/Cr pillaring solution slowly added to } \\
2 \% \text { bentonite suspension sonicated for } 30 \\
\text { minutes at } 35 \mathrm{~Hz} \text { and } 75^{\circ} \mathrm{C}\end{array}$ \\
Fe/Cr0.75(SS) & $5: 15$ & 0.25 & $\begin{array}{l}\text { Fe/Cr pillaring solution sonicated for } 30 \\
\text { minutes at } 35 \mathrm{~Hz} \text { and } 75^{\circ} \mathrm{C}\end{array}$ & $\begin{array}{l}\text { Dry clay directly added to Fe/Cr-pillaring } \\
\text { solution sonicated for } 30 \text { minutes at } 35 \mathrm{~Hz} \\
\text { and } 75^{\circ} \mathrm{C}\end{array}$ \\
\hline
\end{tabular}

Phenol is an important and representative temperature resistant organic pollutant that is toxic even at low concentrations and, if found in natural water, generates harmful chlorine compounds during the disinfection of natural water via chlorination $[6,20,26]$. For this reason, it has become increasingly important to purify water contaminated by phenol and its derivatives in recent years. It seemed to be more effective to use advanced oxidation processes to purify waste water containing organic pollutants that are difficult or impossible to decompose biologically [27]. Among advanced oxidation processes, the activation of hydrogen peroxide by means of a solid catalyst (catalytic wet peroxide oxidation CWPO) is the most promising process, both economically and technologically. Pillared clays have offered an important line of research in obtaining solids responding to the CWPO process [15].

In this study, synthesis of iron/chromium-pillared bentonites was accomplished by using ultrasound treatment during both the aging and the intercalation of the pillaring solution. Furthermore, during intercalation stage the pillaring solution and clay are mixed in three different ways: (1) by adding the pillaring solution directly to the dry clay, (2) by adding the dry clay slowly to the pillaring solution, and (3) by adding the pillaring solution slowly to a $2 \%$ clay suspension. The physicochemical properties of the derived samples were analyzed by SEM-EDS, XRD, nitrogen and carbon dioxide adsorption/desorption, EPR, FTIR, and TG analysis. The catalytic activities of the Fe/Cr-pillared bentonites were assessed for the catalytic wet peroxide oxidation of phenol.

\section{Materials and Methods}

2.1. Materials. Raw bentonite clay (RB) was obtained from Ünye (Turkey) and was used without any further purification or cation exchange. All the chemicals, from Sigma-Aldrich and Merck, were of laboratory reagent grade and used without further purification. Doubly distilled water was used throughout the work.
2.2. Synthesis of Fe/Cr-Pillared Bentonites. Fe/Cr-pillared bentonite synthesis was carried out, with any indicated modifications, according to the procedure of Olaya et al. [9]. Pillaring solutions containing iron and chromium were prepared via dropwise addition (flow rate of $1 \mathrm{~mL} / \mathrm{minute}$ ) of a $0.4 \mathrm{M} \mathrm{NaOH}$ solution into a solution of $\mathrm{FeCl}_{3} \cdot 6 \mathrm{H}_{2} \mathrm{O}$ and $\mathrm{CrCl}_{3} \cdot 6 \mathrm{H}_{2} \mathrm{O}$ salts in either a $15: 5$ or $5: 15 \mathrm{Fe}: \mathrm{Cr}$ molar ratio, producing on $\mathrm{OH}^{-} / \mathrm{Fe}^{3+}+\mathrm{Cr}^{3+}$ ratio of 2.4 . Fe/Crpillaring solutions were aged with ultrasound at $75^{\circ} \mathrm{C}$ for 30 minutes, used an ultrasonic bath (Bandelin Sanorex, operating frequency $35 \mathrm{kHz}$ ). The intercalation process was performed using one of three methods: (1) by directly mixing the pillaring solution and the dry clay, (2) by slowly adding the dry clay to the pillaring solution, or (3) by slowly adding the pillaring solution to a $2 \%$ suspension at of the clay to make a $20 \mathrm{mmol}$ ratio of $\mathrm{Fe}+\mathrm{Cr} / \mathrm{g}$ of clay. The derived suspensions were separated from the liquid phase by centrifugation, and then they were washed to remove the chlorine ions and calcined at $300^{\circ} \mathrm{C}$ (heating ramp of $3^{\circ} \mathrm{C} / \mathrm{min}$ ) for 3 hours after drying at $60^{\circ} \mathrm{C}$ for 16 hours. For a comparison, Fe/Cr-pillared bentonite was prepared by conventional method. Fe/Cr-pillaring solution was prepared to make $\mathrm{Fe} / \mathrm{Cr}$ ratio of $15: 5$ and an $\mathrm{OH} / \mathrm{Fe}+\mathrm{Cr}$ ratio of 2.4 and kept at room temperature for 24 hours before adding it dropwise to the previously prepared $2 \% \mathrm{~m} / \mathrm{m}$ suspension to give a $20 \mathrm{mmol}$ ratio of $\mathrm{Fe}+\mathrm{Cr} / \mathrm{g}$ bentonite, which was then kept at room temperature for 24 hours with stirring. Filtration, drying, and calcination were performed as previously described. The conditions of synthesis and the nomenclature of the solids obtained were summarized in Table 1 .

2.3. Characterization Studies. Scanning electron microscopy (SEM) microphotographs were obtained from powdered samples with a QUANTA 400F Field Emission SEM. The chemical composition of some of the pillared bentonites was determined using a QUANTA 400F Field Emission SEM Energy Dispersive X-ray Spectrometer (EDS). 
TABLE 2: Chemical properties of raw and pillared bentonites.

\begin{tabular}{lccccccc}
\hline \multirow{2}{*}{ Sample code } & \multicolumn{7}{c}{ Metal oxides $\% \mathrm{~m} / \mathrm{m}$} \\
& $\mathrm{SiO}_{2}$ & $\mathrm{Al}_{2} \mathrm{O}_{3}$ & $\mathrm{MgO}$ & $\mathrm{CaO}$ & $\mathrm{K}_{2} \mathrm{O}$ & $\mathrm{Fe}_{2} \mathrm{O}_{3}$ & $\mathrm{Cr}_{2} \mathrm{O}_{3}$ \\
\hline Raw bentonite & 68.1 & 24.3 & 4.52 & 0.79 & 0.33 & 2.04 & 0.00 \\
$\mathrm{Fe} / \mathrm{Cr} 0.75$ & 63.3 & 22.5 & 4.00 & 0.00 & 0.27 & 5.23 & 4.71 \\
$\mathrm{Fe} / \mathrm{Cr} 0.75(\mathrm{D})$ & 65.2 & 21.9 & 4.41 & 0.00 & 0.29 & 3.14 & 5.01 \\
$\mathrm{Fe} / \mathrm{Cr} 0.75(\mathrm{SS})$ & 61.8 & 21.2 & 4.41 & 0.00 & 0.23 & 7.48 & 4.81 \\
$\mathrm{Fe} / \mathrm{Cr} 0.25(\mathrm{D})$ & 64.4 & 20.0 & 4.47 & 0.00 & 0.23 & 3.52 & 7.18 \\
\hline
\end{tabular}

The obtained solid products were characterized using Xray diffraction on a Phillips PW 3710 diffractometer using $\mathrm{Cu} \mathrm{K} \alpha$ radiation $(40 \mathrm{kV}, 40 \mathrm{~mA})$ that ranged between 1 and $70^{\circ} 2 \theta$. Semiquantitative percentages of the clay were calculated by means of mineral intensity factors, as suggested by Yalçin and Bozkaya [28], and based on the external standard method of Brindley [29].

The porous structure of the samples was characterized from nitrogen and carbon dioxide adsorption-desorption isotherms. Nitrogen adsorption/desorption isotherms of the samples were obtained by means of a Quanthrocrome NovaWin gas adsorption system at liquid nitrogen temperature. Carbon dioxide adsorption-desorption isotherms of the samples were obtained by means of a Quantachrome Autosorp 1C gas adsorption system at liquid carbon dioxide temperature. Prior to the measurement, samples were outgassed at a temperature of $250^{\circ} \mathrm{C}$ under high vacuum for $16 \mathrm{~h}$. Specific BET surface area $\left(S_{\mathrm{BET}}\right)$ values were calculated with $0.05<P / P_{0}<0.30$. The specific external surface area $\left(S_{\text {ext }}\right)$ and the micropore volume $\left(V_{\mu, t}\right)$ were obtained using the $t$-plot method. The total pore volume $\left(V_{t}\right)$ was estimated from the adsorption data at a $P / P_{0}$ value of $\sim 0.99$. The Barrett-Joyner-Halenda (BJH) method was applied to the desorption data for $P / P_{0}$ values above 0.20 to determine the mesopore surface area $\left(S_{\mathrm{BJH}}\right)$ and the mesopore volume $\left(V_{\mathrm{BJH}}\right)$ for pores in the 10-500 $\AA$ range. The micropore and mesopore volume distribution as a function of pore size was calculated by Horvath-Kawazoe (HK) and Barrett-JoynerHalenda (BJH) method, respectively. Micropore volume $\left(V_{\mu, \mathrm{HK}}\right)$ values were calculated by Horvath-Kawazoe (HK) method, which was applied for micropore size distribution $[30,31]$.

The Electron paramagnetic resonance (EPR) spectra were recorded in a continuous wave mode using the $\mathrm{X}$ band at room temperature using a Bruker ELEXSYS E580 spectrometer.

The FTIR spectra were obtained using $\mathrm{KBr}$ pellets and a Perkin Elmer BX-FTIR spectrometer, in the range of 400$4000 \mathrm{~cm}^{-1}$. All spectra were collected at room temperature, with a resolution of $4 \mathrm{~cm}^{-1}$. The acidity of the $\mathrm{OH}$-groups was determined by collecting the spectra of the samples after saturating them with benzene by exposing them to benzene steam for 48 hours.

Thermogravimetric analysis (TGA) was performed by heating the samples in air with a flow rate of $80 \mathrm{~mL} / \mathrm{min}$ using a Setaram Labsys TGA/DTA thermal analyzer with a heating rate of $10^{\circ} \mathrm{C} / \mathrm{min}$.
2.4. Catalytic Studies. The catalytic experiments of the wet peroxide oxidation of phenol were performed using a glass batch reactor with a capacity of $500 \mathrm{~mL}$ that had been open to the atmosphere, thermostated at $298 \mathrm{~K}$, and thoroughly stirred. The reactor was charged with $100 \mathrm{~mL}$ of $50 \mathrm{ppm}$ phenol solution and a catalyst (typically, $5.0 \mathrm{~g} / \mathrm{L}$ ). When the required temperature was achieved, the corresponding amount of hydrogen peroxide $(0.1 \mathrm{M}, 6 \mathrm{~mL})$ was added to the reactor to start the reaction. The total reaction time was fixed at 3 hours. Samples were drawn at 60 and 180 minutes and were filtered through a $0.22 \mu \mathrm{m}$ nylon filter. The concentration of phenol was determined using the colorimetric reaction of the samples with the FolinCiocalteau (F-C) reagent (Fluka) based on the test procedure developed by Box [32]. TOC analyses were performed on a Shimadzu VCPN model carbon analyzer (via the combustion method) that had been equipped with an autosampler.

At the end of each trial, a solution was separated from the reactive medium by filtration in order to determine the leaching of iron and chromium during the reaction. The analysis of iron and chromium in solution was determined by atomic absorption, using a Perkin Elmer AA800 Model spectrometer.

\section{Results and Discussion}

3.1. Analysis of SEM-EDS. The scanning electron micrographs of both raw and some pillared bentonites are shown in Figure 1. Some variation in the shape and surface structure of the bentonites, which occurred as a result of converting the raw bentonite to the pillared bentonite, can be seen in the SEM micrographs. The samples Fe/Cr0.75 and Fe/Cr0.25(D) show that there was both greater aggregation and greater cohesion than for the raw bentonites and that the pores between the particles were closed. However, it is seen that the number of pores between the particles increased for both the samples $\mathrm{Fe} / \mathrm{Cr} 0.75(\mathrm{D})$ and $\mathrm{Fe} / \mathrm{Cr}$ 0.75(SS). This observation indicated that the use of ultrasound during intercalation favors the formation of larger pores.

The chemical composition of the raw and the pillared bentonites is reported in Table 2. The pillaring of the raw bentonite by $\mathrm{Fe} / \mathrm{Cr}$ pillars resulted in an increase in the $\mathrm{Fe}_{2} \mathrm{O}_{3}$ and $\mathrm{Cr}_{2} \mathrm{O}_{3}$ content, with complete replacement of the interlayer Ca cations. This increase in the $\mathrm{Fe}_{2} \mathrm{O}_{3}$ and $\mathrm{Cr}_{2} \mathrm{O}_{3}$ content, with a corresponding decrease in the number of exchangeable $\mathrm{Ca}$ cations, indicates the successive replacement of interlayer cations with $\mathrm{Fe} / \mathrm{Cr}$ pillars. Moreover, it is 


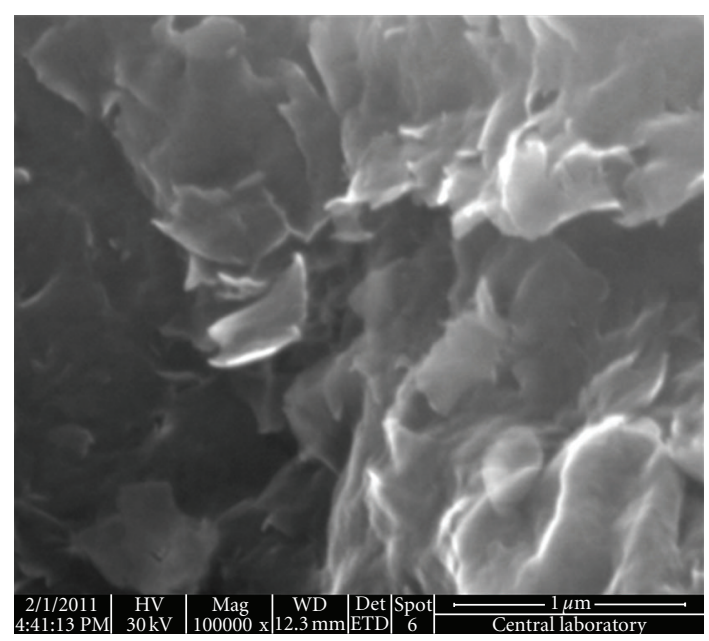

(a)

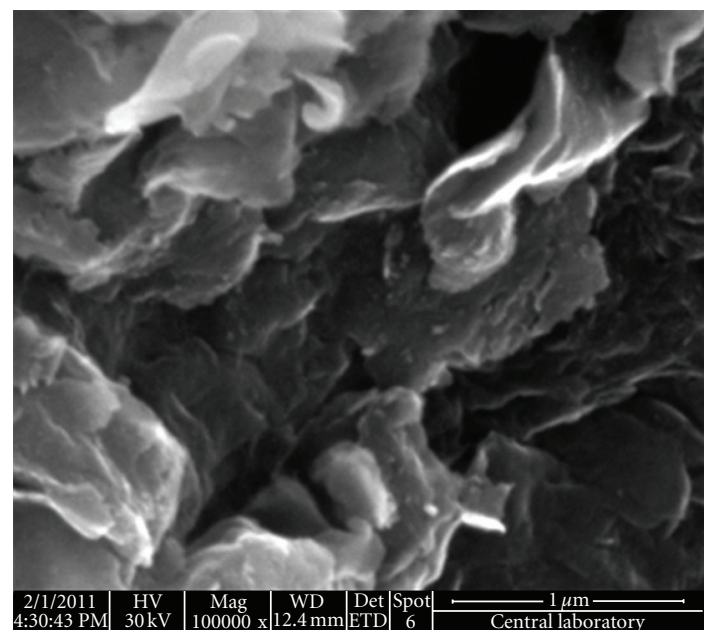

(c)

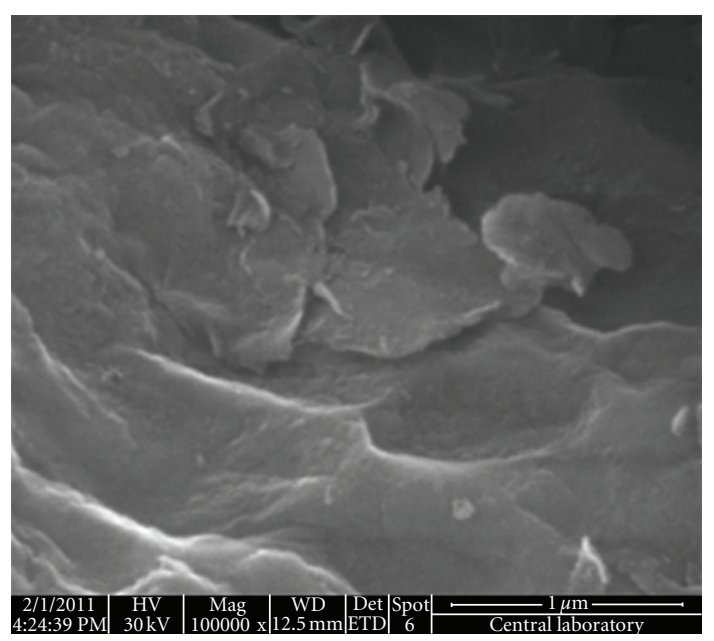

(b)

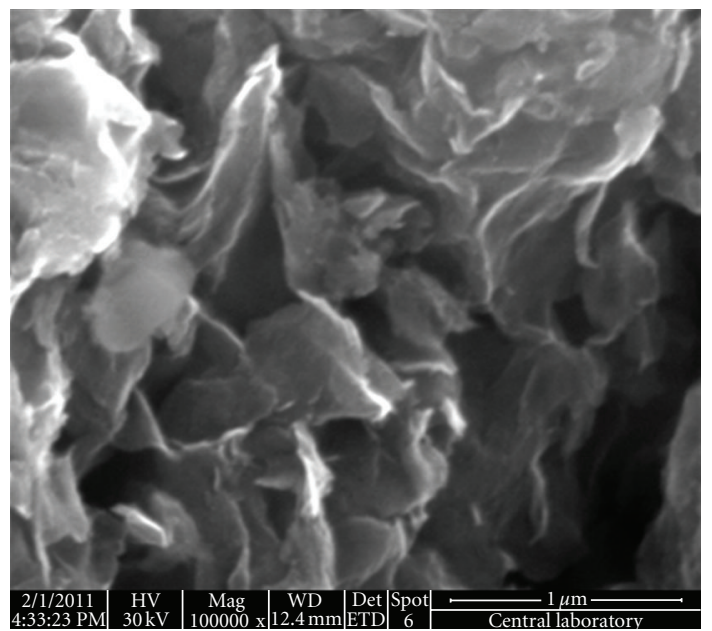

(d)

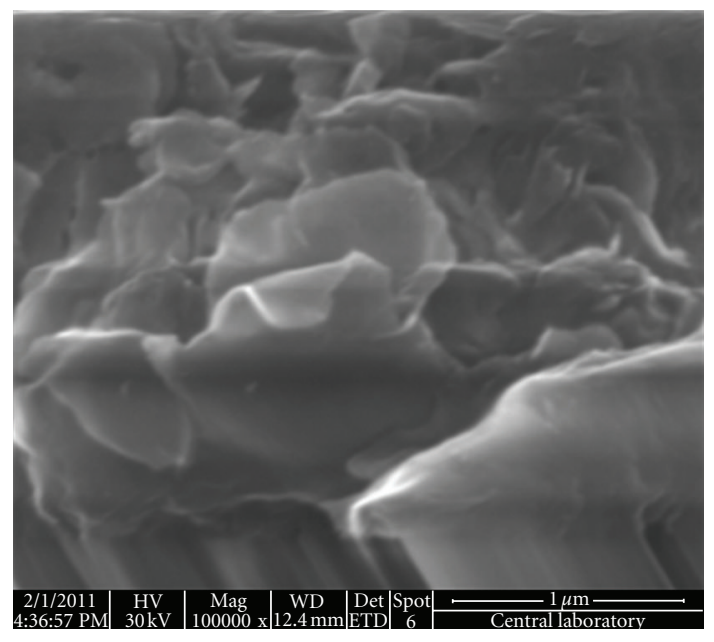

(e)

FIGURE 1: SEM microphotographs of (a) RB, (b) Fe/Cr0.75, (c) Fe/Cr0.75(D), (d) Fe/Cr0.75(SS), and (e) Fe/Cr0.25(D) samples. 


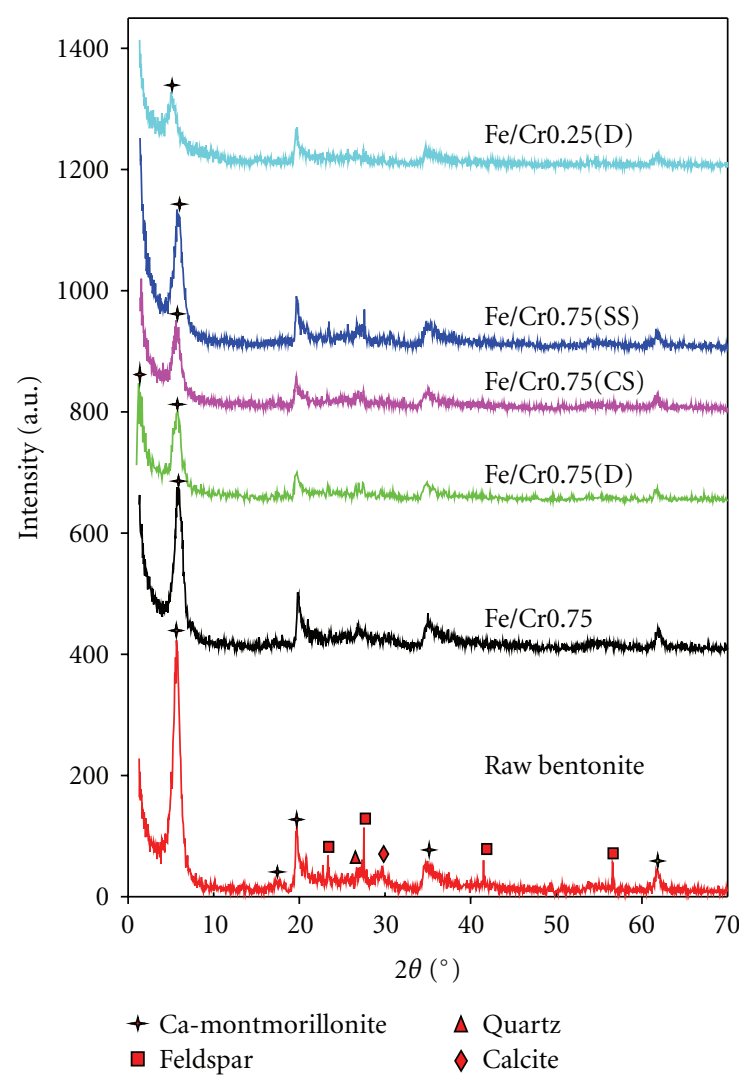

(a)

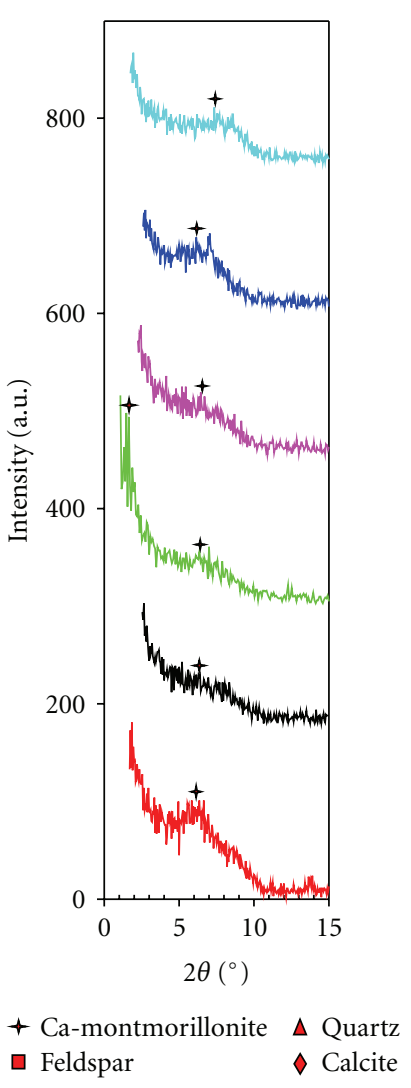

(b)

FIGURE 2: X-ray diffraction patterns of pillared bentonite samples. (a) Fe/Cr-intercalated-pillared bentonites. (b) Fe/Cr-pillared bentonites.

observed that the amount of iron and chromium incorporated into the structure during intercalation depended on the procedure being applied and treatment. Fe/Cr0.75(SS) includes more iron than other samples, with the same $\mathrm{Fe} / \mathrm{Fe}+\mathrm{Cr}$ ratio, prepared by conventional and ultrasound treatments. This observation indicates that there is a beneficial effect of using ultrasound treatment and by adding the pillaring solution slowly to the clay suspension on amount of iron that incorporated into the structure. The use of ultrasound in the intercalation stage probably increases exchange of pillars and improves the dispersion and homogenization of the suspended solids [10]. Furthermore, from EDS analysis results, it was observed that, by changing the $\mathrm{Fe} / \mathrm{Fe}+\mathrm{Cr}$ ratio in the pillaring solution, the $\mathrm{Fe} / \mathrm{Cr}$ ratio in pillared clay could be changed; the success of the replacement of iron and chromium in the structure was increased by pillaring with a solution containing an $\mathrm{Fe} / \mathrm{Fe}+$ Cr ratio of 0.75 .

3.2. X-Ray Diffraction Patterns. The XRD patterns of Fe/Crpillared bentonites, together with those of raw and $\mathrm{Fe} / \mathrm{Cr}$ intercalated bentonites, are shown in Figure 2. Basal spacing $\left(\mathrm{d}_{001}\right)$ values are summarized in Table 3 . The reflection angle (20) of raw bentonite at the 001 plane is determined as $5.65^{\circ}$, corresponding to a basal spacing $\left(\mathrm{d}_{001}\right)$ value of $15.6 \AA$. In accordance with the results found in the literature, it is
TABLE 3: Basal spacing $\left(\mathrm{d}_{001}\right)$ values of raw and intercalated/pillared bentonites.

\begin{tabular}{lcc}
\hline Sample code & \multicolumn{2}{c}{$\mathrm{d}_{001}(\AA)$} \\
& Intercalated & Pillared \\
\hline Raw bentonite & 15.6 & 14.7 \\
Fe/Cr0.75 & 15.6 & - \\
Fe/Cr0.75(D) & $68.0-15.7$ & $54.2-13.7$ \\
Fe/Cr0.75(CS) & 15.6 & - \\
Fe/Cr0.75(SS) & 15.8 & 14.1 \\
Fe/Cr0.25(D) & 17.3 & 12.0 \\
\hline
\end{tabular}

observed that the bentonite samples possessed the bentonite characteristic peaks at angles $(2 \theta) 5.6^{\circ}, 17.7^{\circ}, 20^{\circ}, 35^{\circ}$, and $62^{\circ}$ that were protected, even though they were calcined at $300^{\circ} \mathrm{C}[29,33]$. Other peaks were observed that represented impurities like feldspar (15\%) at the angles $(2 \theta) \sim 20.8^{\circ}$, $27.5^{\circ}, 41.4^{\circ}$, and $56.4^{\circ}$; quartz $(2 \%)$ at $26.7^{\circ}$; and calcite $(1 \%)$ at $29.6^{\circ}$ [29].

However, at intercalation stage, other than $\mathrm{Fe} / \mathrm{Cr} 0.75(\mathrm{D})$ that is obtained by adding pillaring solution directly to the dry clay, the samples that were synthesized by both conventional and ultrasound treatments were found to possess similar basal spacing $\left(\mathrm{d}_{001}\right)$ values as the $2 \theta$ value 


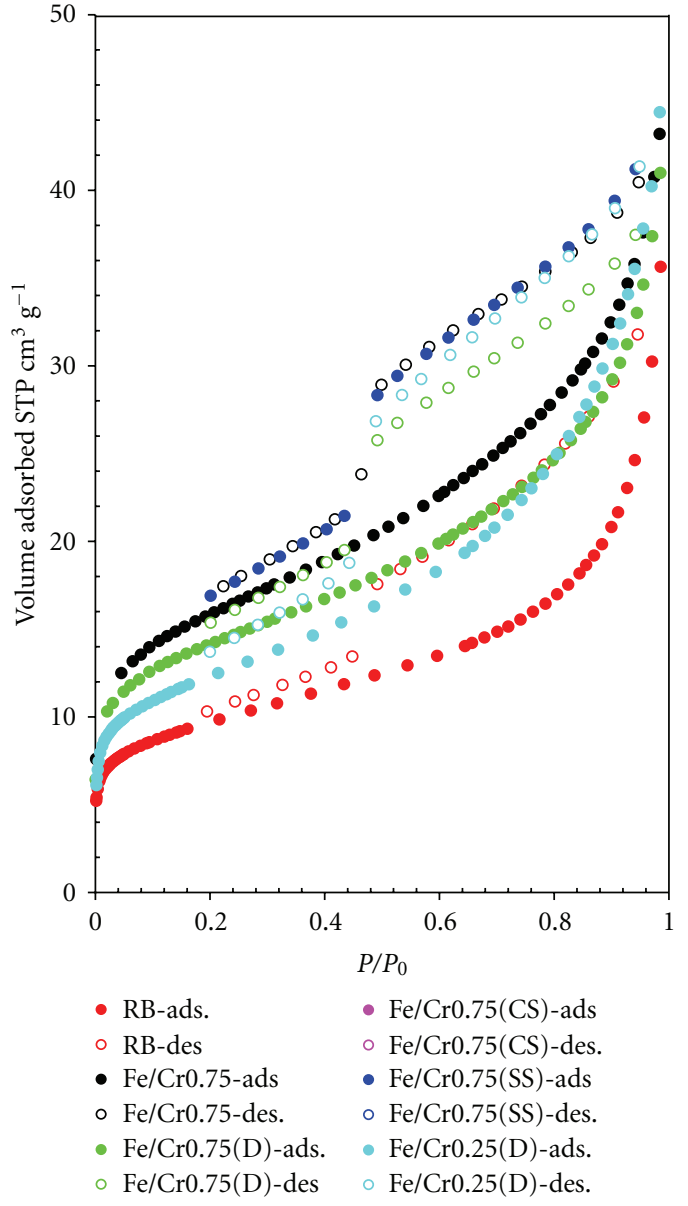

(a)

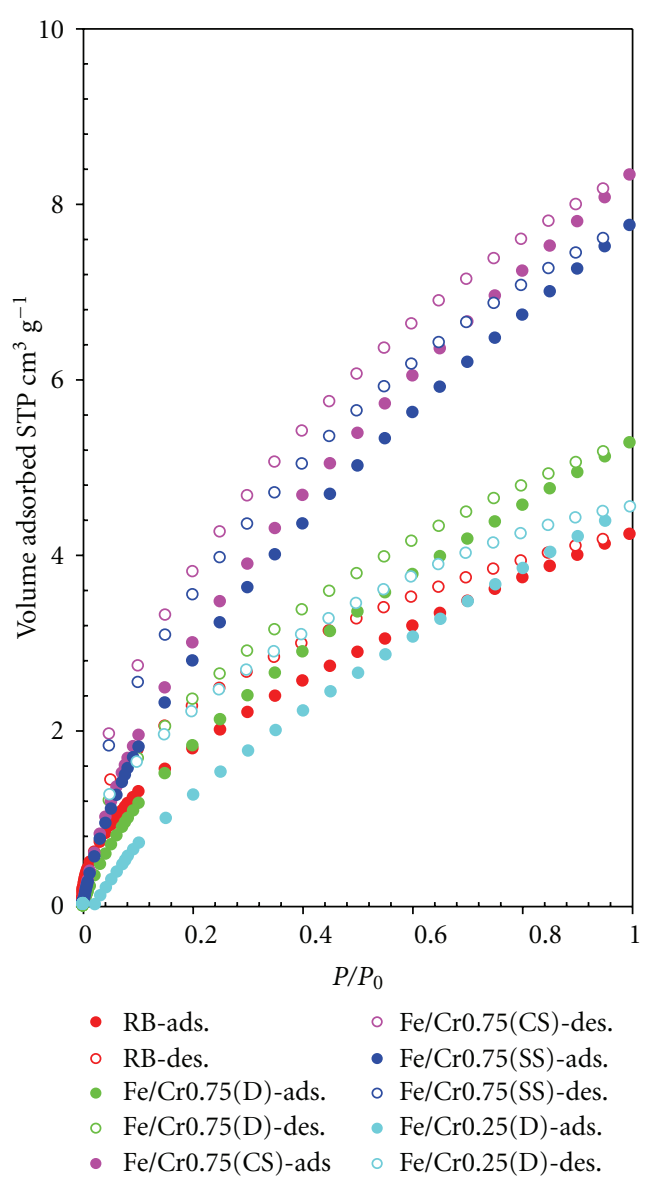

(b)

FIGURE 3: (a) Nitrogen adsorption/desorption isotherms. (b) Carbon dioxide adsorption/desorption isotherms of RB and Fe/Cr-pillared bentonite samples.

of raw bentonite, 15.6-15.8 $\AA$ (see Table 3), according to Xray diffraction patterns. These values might result from the formed small $\mathrm{Fe} / \mathrm{Cr}$ pillars as indicated in the related literature [25]. Furthermore, the identical basal spacing observed for these intercalated bentonites indicates the presence of a similar intercalating species in the pillaring solution. However, two peaks can be observed at the reflection angles (20) $1.29^{\circ}$ and $5.64^{\circ}$ for the $\mathrm{Fe} / \mathrm{Cr} 0.75(\mathrm{D})$, with basal spacing $\mathrm{d}_{001}$ values of $68.5 \AA$ and $15.7 \AA$, respectively. These results were in accordance with those of the studies related to delaminated iron-intercalated clays $[23,34,35]$. However, the delamination behavior was not observed in the other intercalated clays, as previously indicated in the literature $[36,37]$. Contrarily, Fe/Cr0.25(D) sample showed a decrease in peak intensities and an increase in basal spacing values with respect to raw bentonite in the region of $2 \theta$ between 1 and $10^{\circ}$. This result indicates that larger $\mathrm{Fe} / \mathrm{Cr}$ pillars are formed by increasing the chromium content of the $\mathrm{Fe} / \mathrm{Cr}$ pillaring solution [38].

Heat treatment of the raw bentonite at $300^{\circ} \mathrm{C}$ for $3 \mathrm{~h}$ decreased the $\mathrm{d}_{001}$ spacing to $14.7 \AA$, indicating retention of the layered structure at higher temperatures (Figure 2(b), Table 2). Strong electrostatic and other forces between the clay layers can help retain the layer structure of the clay materials at higher temperatures. On the other hand, after calcination at $300^{\circ} \mathrm{C}$, when comparing the patterns of X-ray diffraction of sample synthesized by conventional method and the patterns of X-ray diffraction of samples obtained by ultrasound treatment, distinctive d-spacing peaks were not observed at XRD patterns of $\mathrm{Fe} / \mathrm{Cr} 0.75$ and $\mathrm{Fe} / \mathrm{Cr} 0.75$ (CS) samples. The delaminated structure of $\mathrm{Fe} / \mathrm{Cr} 0.75(\mathrm{D})$ was preserved, while the basal spacing value of $\mathrm{Fe} / \mathrm{Cr} 0.25$ (SS) decreased from $15.8 \AA$ to $14.1 \AA$ after $300^{\circ} \mathrm{C}$ calcination (Table 3).

3.3. $\mathrm{N}_{2}$ - and $\mathrm{CO}_{2}$-Adsorption/Desorption Studies. The specific surface areas, the pore volumes, micropore and mesopore size distribution of the raw, and the pillared bentonite samples were determined by nitrogen adsorption/desorption at liquid nitrogen temperature. Carbon dioxide adsorption/desorption isotherms were also performed to determine the distribution of micropore and mesopore size distributions. 


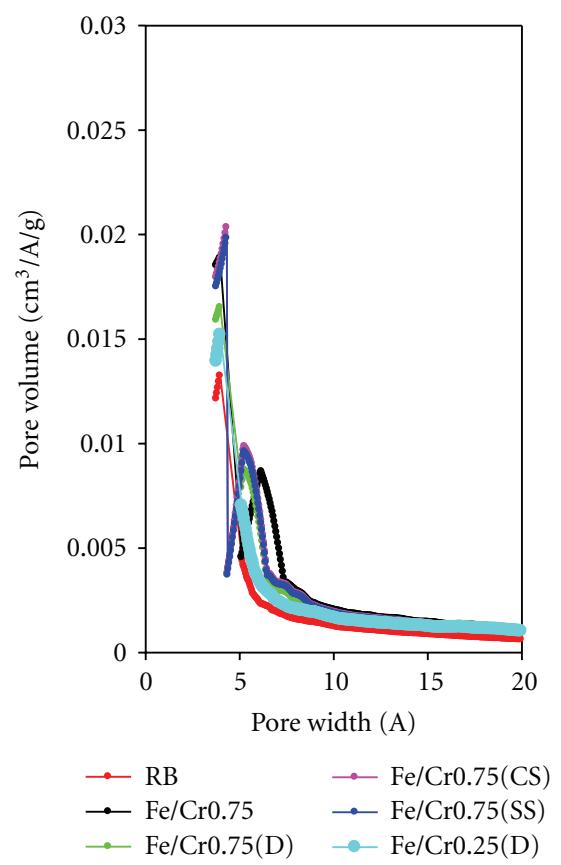

(a)

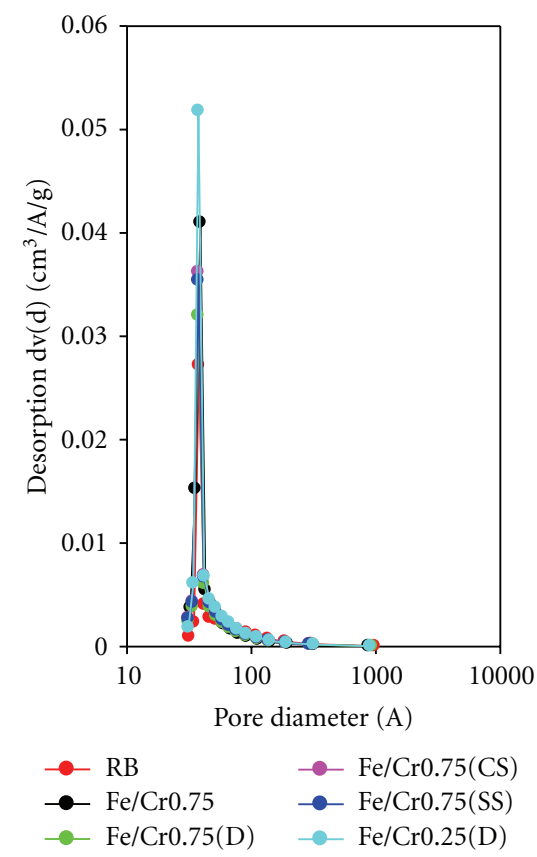

(c)

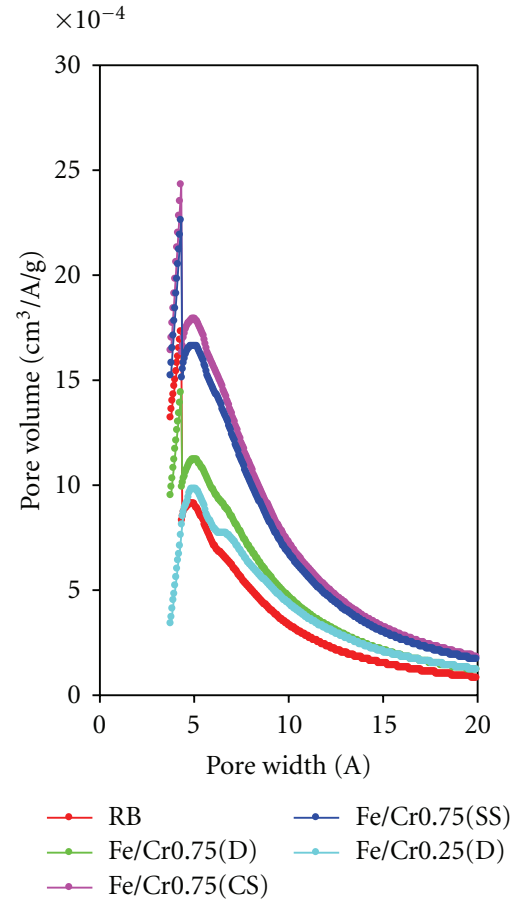

(b)

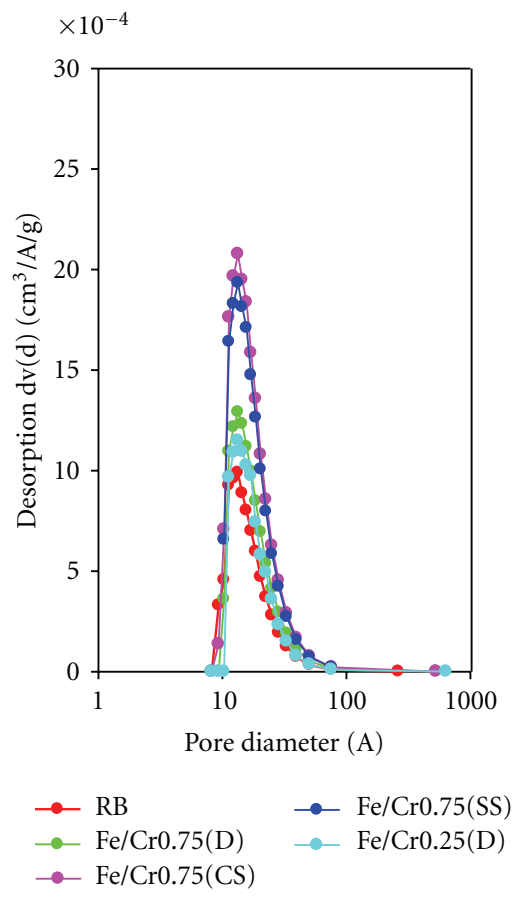

(d)

Figure 4: HK-method pore size distribution curves (a) from nitrogen sorption data and (b) carbon dioxide sorption data and BJH-method pore size distribution curves (c) from nitrogen sorption data and (d) carbon dioxide sorption data.

Figure 3(a) presents the nitrogen adsorption-desorption isotherms. Both the pillared and raw bentonites possessed type II adsorption isotherms, according to IUPAC classification. The hysteresis found in these materials is H3 type, according to IUPAC classification, and is attributed to either slit-shaped pores or plate-like particles with space between the parallel plates [30,31].

The textural properties of pillared bentonites are presented in Table 4. It is seen that all pillared bentonites with $\mathrm{Fe} / \mathrm{Fe}+\mathrm{Cr}$ ratio of 0.75 have similar textural properties and 


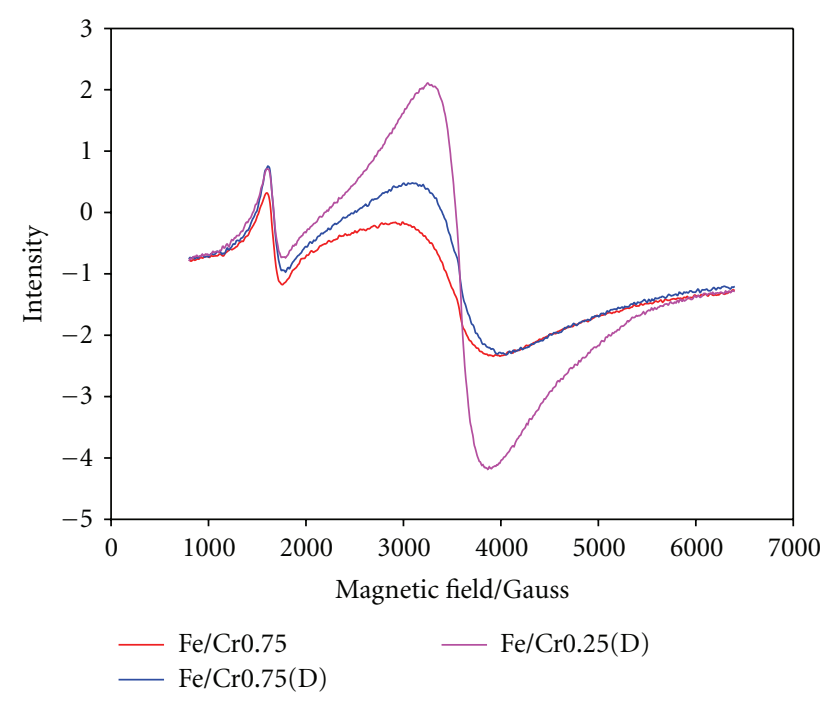

Figure 5: EPR spectra of the Fe/Cr0.75, Fe/Cr0.75(D), and Fe/ Cr0.25(D) samples.

these properties do not change remarkably with different synthesis conditions. The similar textural properties of these pillared bentonites, other than the Fe/Cr0.75(D) sample, may be explained by the formation of a similar sized basal spacing and similar dispersions of the pillars in the interlayer region. However, the $\mathrm{Fe} / \mathrm{Cr} 0.25(\mathrm{D})$ sample has a greater $\mathrm{d}_{001}$ value than the other samples, but it has a lower $S_{\mathrm{BET}}$ value, which is associated with the amount and dispersion of the pillars among the interlayers of this sample. Furthermore, this result is supported by the $\mathrm{Fe} / \mathrm{Cr} 0.25(\mathrm{D})$ sample possessing $V_{m}$ values lower than both the natural and the other pillared bentonites (Table 4). In addition, when the textural properties of the $\mathrm{Fe} / \mathrm{Cr} 0.75(\mathrm{D}), \mathrm{Fe} / \mathrm{Cr} 0.75(\mathrm{CS}$ ), and $\mathrm{Fe} / \mathrm{Cr} 0.75$ (SS) samples are compared, it is seen that the sample Fe/Cr0.75(CS) has the greatest surface area and pore volume values. These results indicated that the micro-pores formation increases by slow addition of the dry clay to the pillaring solution with ultrasound treatment at intercalation stage.

Figure 3(b) shows the carbon dioxide adsorption-desorption isotherms of the samples. Both the Fe/Cr0.75(D) and $\mathrm{Fe} / \mathrm{Cr} 0.25(\mathrm{D})$ samples have similar adsorption capacities to the raw bentonite, while the $\mathrm{Fe} / \mathrm{Cr} 0.75(\mathrm{CS})$ and $\mathrm{Fe} / \mathrm{Cr} 0.75$ (SS) samples have higher values than the other samples. It was obtained that the adsorption capacities evaluated from carbon dioxide adsorption data were comparable but smaller than the corresponding adsorption capacities obtained from nitrogen adsorption.

The HK-micropore and BJH-mesopore size distributions obtained from the nitrogen adsorption isotherms for the samples that were studied are presented in Figure 4, along with the comparison to the corresponding distributions from the carbon dioxide data. As can be seen from Figure 4, there is a good agreement between the pore size distributions of the adsorbents studied. Raw and all the pillared bentonite samples have two modes of distribution of $4.32 \AA$ and broad

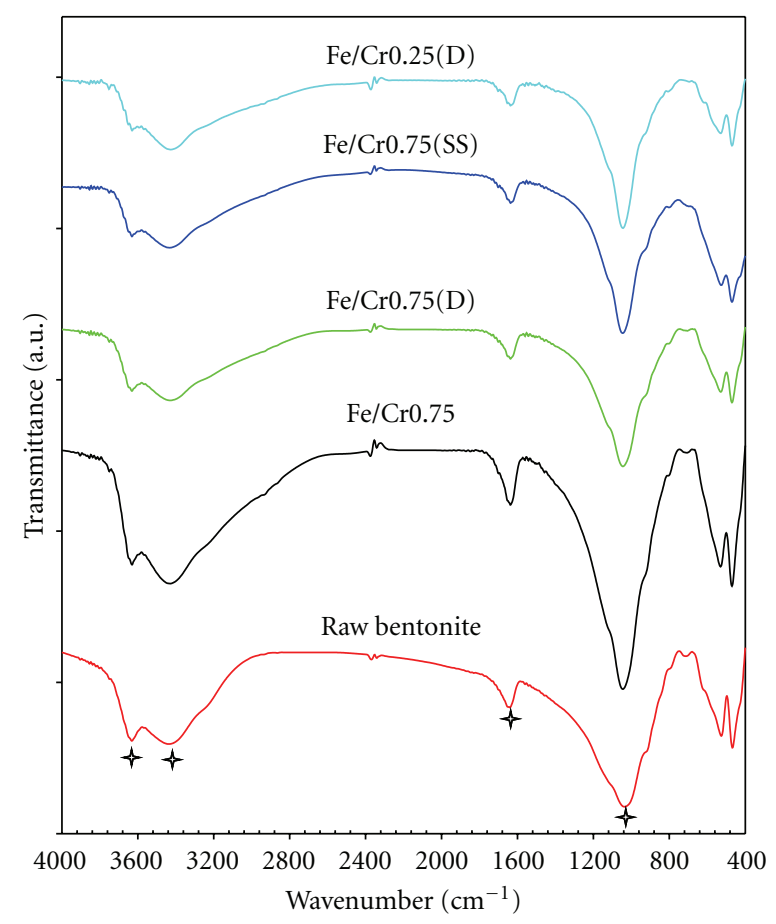

FIgURE 6: FTIR spectra of raw and pillared bentonite samples.

5-8 (Figures 4(a) and 4(b)). This behavior indicates the presence of two types of micropore. As clearly shown in Figure 4, no important increases to the volume adsorbed by the micropores resulted from the pillaring processes.

The BJH-mesopore size distribution peaks obtained from nitrogen adsorption are relatively narrow, which allowed us to use the average pore diameter on the maximum of the pore size distribution as the characteristic parameter (Figure $4(\mathrm{c})$ ). However, a larger $\mathrm{BJH}$-mesopore size distribution dispersion is observed for the carbon dioxide adsorption isotherm (Figure 4(d)). It was observed that the pore volumes given by nitrogen isotherms were greater than those of carbon dioxide. The observed differences may be caused by differing sensitivities of the isotherms to different types of porosity; for example, nitrogen adsorption at $77 \mathrm{~K}$ may not be as sensitive as carbon dioxide adsorption at $273 \mathrm{~K}$ to the same types of microporosity when the micropore size distribution is large [39].

3.4. EPR Analysis. Two characteristic $\mathrm{Fe}^{3+}$ signals were observed in smectite-type minerals with values of $g$ equal to 4.3 and 2.0 in the EPR analysis (Figure 5). The presence of isolated $\mathrm{Fe}^{3+}[19,40]$ with either tetrahedral or octahedral coordination is associated to the signal of $g$ equal to 4.3, which for smectite minerals is associated with iron located inside of the clay sheets (iron exchanging aluminum in the octahedral layers). In contrast, the presence of clusters of iron corresponds with the signal of $g$ equal to 2.0. In this work, the signal observed at a $g$ of 2.0 did not change based on the process and the employed $\mathrm{Fe} / \mathrm{Fe}+\mathrm{Cr}$ ratio, but the intensity of the signal observed at a $g$ of 4.3 was greater for the $\mathrm{Fe} / \mathrm{Cr} 0.25(\mathrm{D})$ sample. 


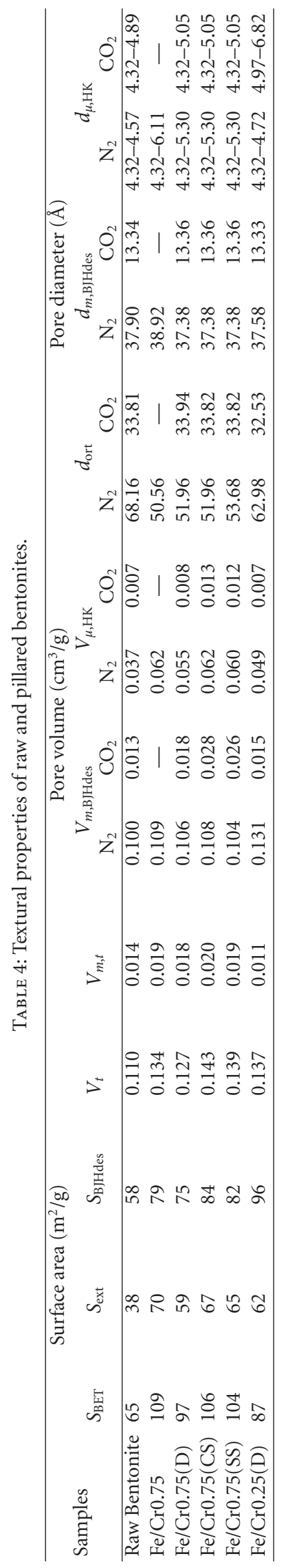




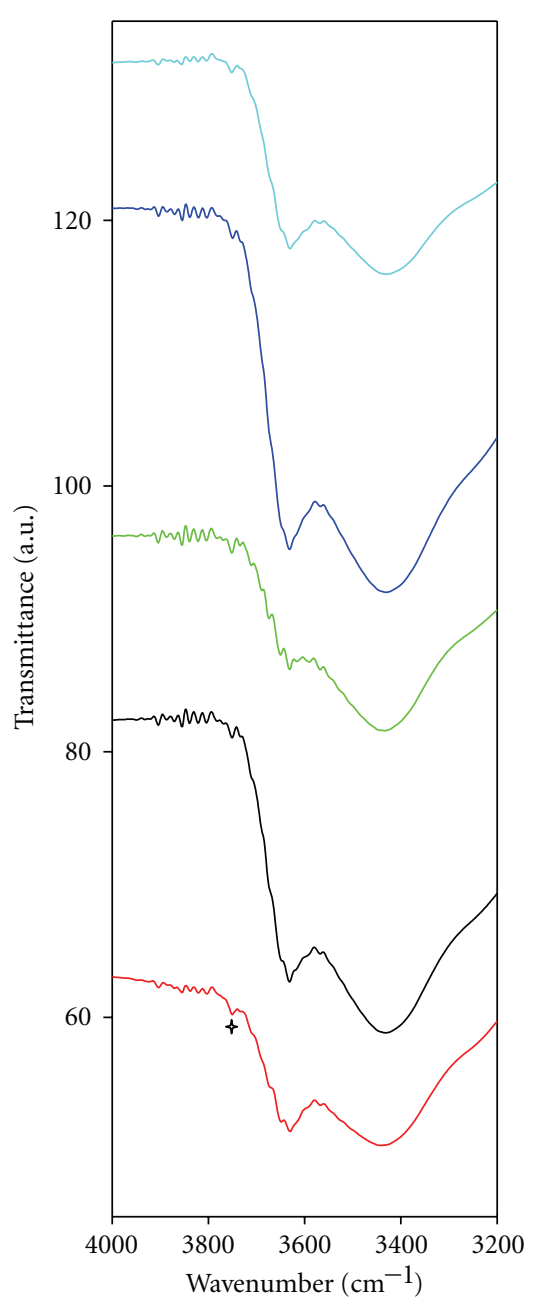

(a)

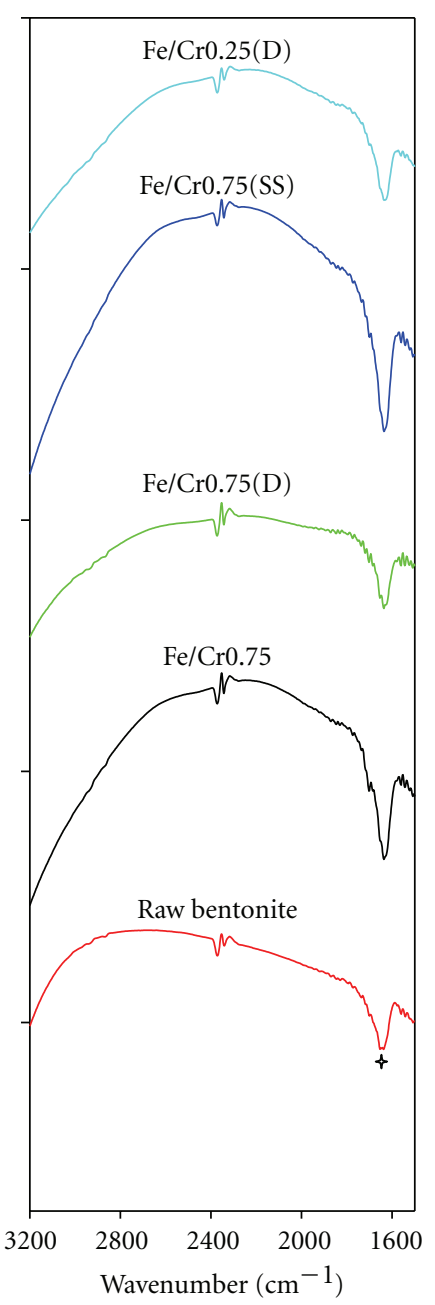

(b)

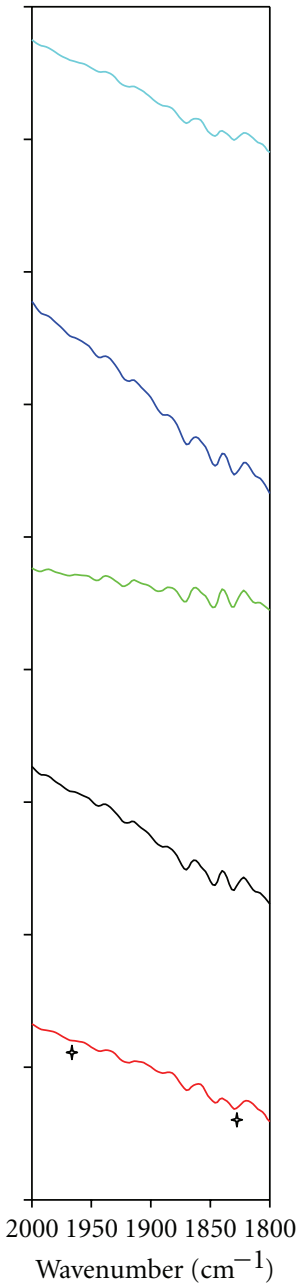

(c)

FIGURE 7: FTIR spectra of raw and pillared bentonite samples after benzene adsorption: (a) 4000-3200 $\mathrm{cm}^{-1}$, (b) $3200-1600 \mathrm{~cm}^{-1}$, and (c) $2000-1800 \mathrm{~cm}^{-1}$.

3.5. FTIR Spectrums. Figure 6 shows the FTIR spectra (400$4000 \mathrm{~cm}^{-1}$ ) of both natural and all pillared bentonites. The wave numbers and assignments of the main vibrational peaks come from values found in the literature [41-43]. There were few IR spectral differences between the natural and $\mathrm{Fe} / \mathrm{Cr}$-pillared bentonites which implied that the modified clay material kept its original structural configuration after pillaring. The appearance of a broad peak at approximately $3435 \mathrm{~cm}^{-1}$ corresponds to the $\mathrm{O}-\mathrm{H}$ stretching mode of the absorbed water, with a simultaneous shift to lower wavenumbers and an increase in width. This behavior indicates an increase in the interlayer water content due to the replacement of inorganic cations with the $\mathrm{Fe} / \mathrm{Cr}$ pillars [24, 42]. Also, the decrease of the peaks at $3631 \mathrm{~cm}^{-1}$ can be detected for all of the pillared bentonites, suggesting that the $\mathrm{Fe} / \mathrm{Cr}$ pillars could link with $\mathrm{Al}-\mathrm{O}$ in the alumina octahedral sheet. The peak at $1640 \mathrm{~cm}^{-1}$ can be associated to the bending vibration of the water and shifted to $1636 \mathrm{~cm}^{-1}$ after pillaring. Also, a shift of the peak of raw bentonite at $1036 \mathrm{~cm}^{-1}$ towards higher frequencies was nearly the same in all pillared bentonites $\left(1044 \mathrm{~cm}^{-1}\right)$. This change has been previously related to a change in the symmetry of the surface $\mathrm{Si}-\mathrm{O}-\mathrm{Si}$ vibration, which is perhaps associated with a change in the electric field near the Si groups due to the proximity of the more positively charged Fe/Cr pillars [44]. Also, the bands at 526 and $467 \mathrm{~cm}^{-1}$ can be ascribed to the $\mathrm{Al}-\mathrm{O}$ stretching and $\mathrm{Si}-\mathrm{O}$ bending vibrations shifted to higher wavenumbers $\left(529-469 \mathrm{~cm}^{-1}\right)$ all pillared bentonites. Absence of additional peaks suggests that no bond formation occurs between bentonite and Fe/Cr-pillars [45].

Adsorption of benzene shows that no strong acid sites are present in all samples (Figure 7). However, because of the interaction between benzene and silanols, there is a small peak observed at $3756 \mathrm{~cm}^{-1}$ for all samples (Figure 7(a)). It was observed that the peak intensity at $3756 \mathrm{~cm}^{-1}$ increased slowly after pillaring with the Fe/Cr pillars. Furthermore, it is seen that after benzene adsorption the peak at $1640 \mathrm{~cm}^{-1}$ increased in intensity (Figure $7(\mathrm{~b})$ ). There are two small peaks observed in the all samples, at $1831 \mathrm{~cm}^{-1}$ and $1968 \mathrm{~cm}^{-1}$ from the $\mathrm{C}-\mathrm{H}$ out-of-plane bending vibration 


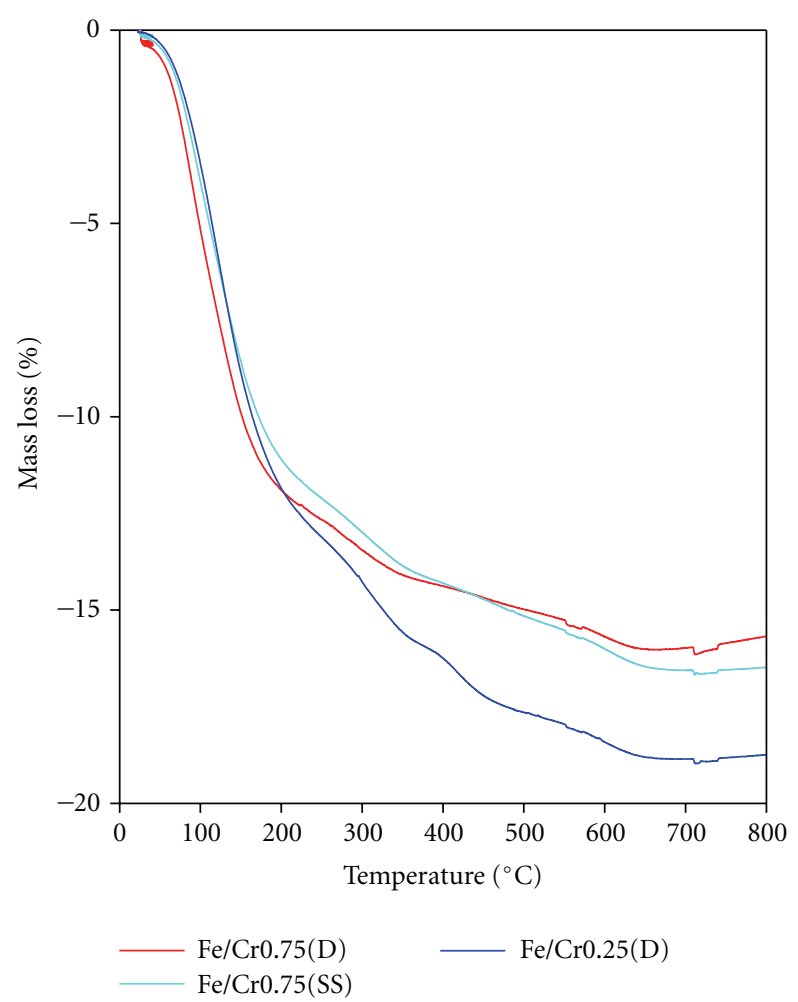

FIGURE 8: TG curves of some pillared bentonite samples.

(Figure 7(c)) [43]. The increase in peak intensity is more distinctive at $1640 \mathrm{~cm}^{-1}$, especially for the Fe/Cr0.75 and Fe/Cr0.75(SS) samples. This result indicates that the acidities of these samples are greater than the others. After benzene adsorption to the pillared bentonites, the changes in the FTIR spectra implied that there are a few acid sites in the pillared bentonites.

3.6. Thermogravimetric Analysis. In order to investigate the thermal behavior of the air-dried Fe/Cr0.75(D), Fe/ Cr0.75(SS), and Fe/Cr0.25(D) samples, the thermogravimetric (TG) analyses were carried out in the temperature range of $25-800^{\circ} \mathrm{C}$. Pillared bentonites show similar weight loss behavior in the TG analysis (Figure 8). The pillared bentonites show high initial weight losses which gradually decrease at higher temperatures. Two weight loss regions have been observed for all samples in the range of 25$300^{\circ} \mathrm{C}$ and $300-700^{\circ} \mathrm{C}$. The major weight loss occurred at $25-300^{\circ} \mathrm{C}$ is due to the removal of water molecules present in the interlayer. This dehydration process is one of the characteristics of clay minerals [46]. However, the weight losses observed in the range of $300-700^{\circ} \mathrm{C}$ are attributed to the water molecules coordinated to the pillars as well as the dehydroxylation of the pillars and clay sheets and can be correlated indirectly to the quantity and distribution of the Fe/Cr-pillars. Contrarily, the total weight loss with the $\mathrm{Fe} / \mathrm{Cr} 0.25(\mathrm{D})$ sample is higher than that of the Fe/Cr0.75(D) and $\mathrm{Fe} / \mathrm{Cr} 0.75$ (SS) sample, which suggests that a significantly higher amount of water is present in the micropores of the two samples. The Fe/Cr0.75(D) and Fe/Cr0.75(SS) samples showed similar total weight losses.

3.7. Catalytic Activity for the Wet Peroxide Oxidation of Phenol. After the synthesis and characterization, the obtained Fe/Cr-pillared bentonites were tested for catalytic activity for the catalytic wet hydrogen peroxide oxidation of phenol under the conditions defined previously. For the purpose of comparison, a control reaction was conducted under the same conditions using only raw bentonite. The quantity of phenol removed using $\mathrm{RB}, \mathrm{Fe} / \mathrm{Cr} 0.75$, Fe/Cr0.75(D), $\mathrm{Fe} / \mathrm{Cr} 0.75(\mathrm{SS})$, and Fe/Cr0.25(D) in the presence of $\mathrm{H}_{2} \mathrm{O}_{2}$ is presented in Figure 9. Comparing the oxidation data of the raw and pillared bentonites reveals that pillaring effectively increases the activity of the bentonites. This catalytic activity can be mainly related to the metal content and textural properties. The catalytic activity increases for the solids treated with the active metals. When the oxidation activities of samples synthesized via the conventional method are compared to the activities of samples synthesized by ultrasonication, the sample synthesized by the conventional method, Fe/Cr0.75, showed a higher activity than the other pillared samples (Figure 9). The Fe/Cr0.75 sample resulted in a conversion of $50 \%$ of the phenol after $3 \mathrm{~h}$. The phenol conversions of the Fe/Cr0.75(D), Fe/Cr0.75(SS), and Fe/Cr0.25(D) samples were 34,26 , and $40 \%$, respectively over $3 \mathrm{~h}$. The total organic carbon conversion was 3, 31, 26, 26, and 30\% for RB, Fe/Cr0.75, Fe/Cr0.75(D), Fe/Cr0.75(SS), and Fe/Cr0.25(D) catalysts, respectively, over 3 hours. According to these results, proper number of active sites and their distribution on the catalyst surface is more important for catalyst activity in TOC conversion than the metal content in Fe/Crpillared bentonites. Sample Fe/Cr0.75(SS) with fairly high iron and chromium content has the small activity as the other pillared bentonites with lower metal content. Also, these results indicate that, for the complete degradation of phenol under the specified condition, a 3-hour reaction time is inadequate for Fe/Cr0.75 and Fe/Cr0.25(D) samples. The catalytic behavior in phenol oxidation in pillared clays has been recently reported in the literature. In this regard, Carriazo et al. [47] found $100 \%$ phenol conversion in less than an hour, and high TOC conversion value (55\%) using Al-Ce-Fe-pillared clays. Similarly, Sanabria et al. [48] found total fenol conversion and high TOC conversion (49-53\%) in two hours using $\mathrm{Al} / \mathrm{Fe}$-pillared clays.

To verify the chemical stability of the materials that were synthesized during this investigation, the presence of inorganic cations in the reaction mixture was analyzed. The obtained AAS confirmed that the iron concentrations in the filtrates taken after $3 \mathrm{~h}$ of the reaction did not exceed $0.11 \mathrm{ppm}$. This value was lower than those reported for $\mathrm{Al}, \mathrm{Al}-\mathrm{Fe}-$, $\mathrm{Al}-\mathrm{Ce}-\mathrm{Fe}-$, and $\mathrm{Al}-\mathrm{Fe}-\mathrm{Ce}$-pillared clays synthesized by the conventional, ultrasound, and microwave method $[6,19,49]$, thus demonstrating the stability of the active phase. However, chromium concentrations for the Fe/Cr0.75, Fe/Cr0.75(D), and Fe/Cr0.25(D) samples were observed as $24.08 \pm 0.34,24.53 \pm 0.16$, and 80.13 $\pm 1.27 \mathrm{ppm}$, respectively, indicating that iron pillars are more stable than chromium pillars. However, the catalytic 


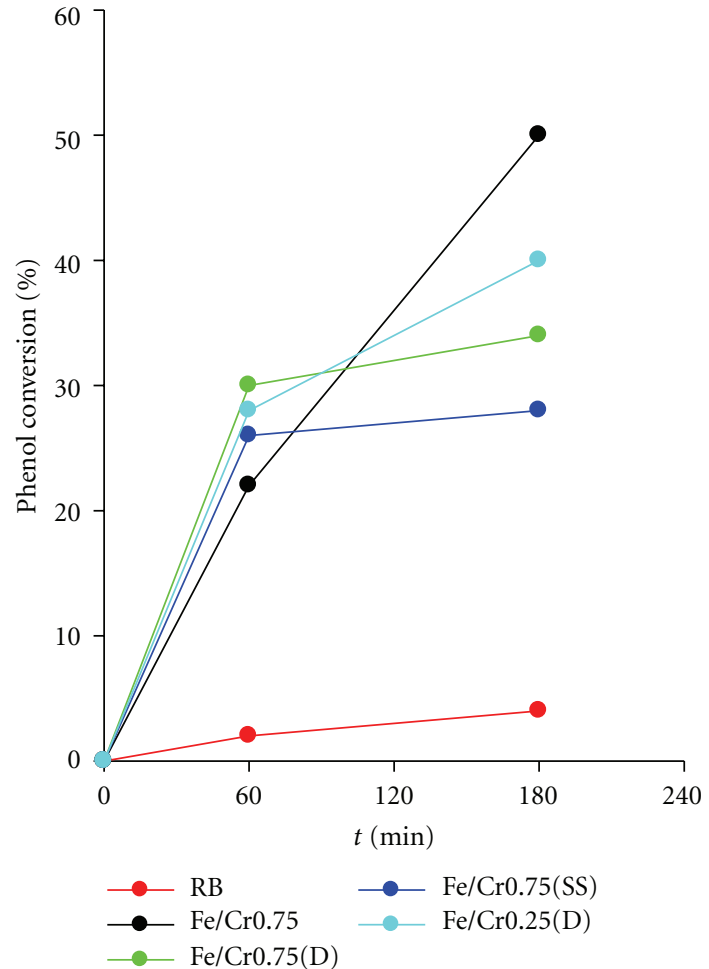

(a)

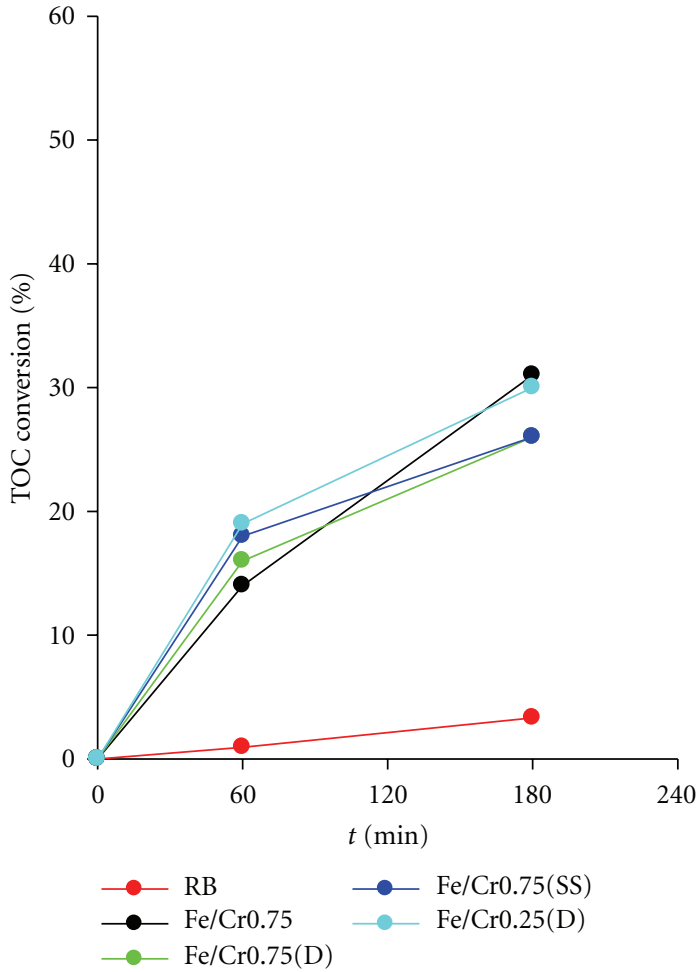

(b)

Figure 9: Catalytic activity for the raw and pillared bentonites with ultrasound and conventional method. (a) Phenol conversion. (b) TOC conversion at atmospheric pressure and at $25^{\circ} \mathrm{C}$.

behavior in catalytic wet peroxide oxidation of phenol in Fe/Cr-pillared clays has not been recently reported in the literature.

\section{Conclusions}

The synthesis of Fe/Cr-pillared bentonites starting from either a $2 \%$ clay suspension or dry clay and using ultrasound treatment during both the aging and intercalation steps of the pillaring solution allows a considerable decrease in the volume of water and the synthesis times compared with the conventional synthesis method. The results of the XRD and adsorption-desorption isotherms analysis showed that pillaring caused a small increase in basal spacing $\left(\mathrm{d}_{001}\right)$ (except of occurring delamination synthesized by ultrasonic treatment and sample that is directly added to the pillaring solution of dry clay), surface area, and pore volume values. TG analysis shows two stages of weight loss due to dehydration-dehydroxylation processes. In addition, the results of the characterizations and catalytic tests carried out for the Fe/Cr-pillared bentonites synthesized by means of ultrasound treatment displayed similar physicochemical characteristics and smaller phenol conversion than the $\mathrm{Fe} / \mathrm{Cr}$-pillared bentonite synthesized by the conventional method in this study.

\section{Acknowledgment}

This research was partially supported by the Scientific Research Project Department of Mehmet Akif Ersoy University (Project code 0107-NAP-10).

\section{References}

[1] J. T. Kloprogge, "Synthesis of smectites and porous pillared clay catalysts: a review," Journal of Porous Materials, vol. 5, no. 1, pp. 5-41, 1998.

[2] A. Gil, L. M. Gandía, and M. A. Vicente, "Synthesis and catalytic application of pillared clays," Catalysis ReviewsScience and Engineering, vol. 42, no. 1-2, pp. 145-212, 2000.

[3] F. Bergaya, A. Aouad, and T. Mandalia, "Pillared clays," in Handbook of Clay Science, F. Bergaya, B. K. G. Theng, and G. Lagaly, Eds., pp. 393-422, Elsevier, Amsterdam, The Netherlands, 2006.

[4] A. Gil, S. A. Korili, R. Trujillano, and M. A. Vicente, Eds., Pillared Clays and Related Catalysts, Springer, 2010.

[5] A. Aouad, T. Mandalia, and F. Bergaya, "A novel method of Alpillared montmorillonite preparation for potential industrial up-scaling," Applied Clay Science, vol. 28, no. 1-4, pp. 175$182,2005$.

[6] A. Olaya, S. Moreno, and R. Molina, "Synthesis of pillared clays with Al13-Fe and Al13-Fe-Ce polymers in solid state assisted by microwave and ultrasound: characterization and catalytic activity," Applied Catalysis A, vol. 370, no. 1-2, pp. $7-$ $15,2009$. 
[7] V. Singh, V. Sapehiyia, and G. L. Kad, "Ultrasound and microwave activated preparation of $\mathrm{ZrO} 2$-pillared clay composite: catalytic activity for selective, solventless acylation of 1,n-diols," Journal of Molecular Catalysis A, vol. 210, no. 1-2, pp. 119-124, 2004.

[8] M. C. Jiménez de Haro, J. L. Pérez-Rodríguez, J. Poyato et al., "Effect of ultrasound on preparation of porous materials from vermiculite," Applied Clay Science, vol. 30, no. 1, pp. 11-20, 2005.

[9] A. Olaya, S. Moreno, and R. Molina, "Synthesis of pillared clays with aluminum by means of concentrated suspensions and microwave radiation," Catalysis Communications, vol. 10, no. 5, pp. 697-701, 2009.

[10] N. R. Sanabria, R. Molina, and S. Moreno, "Effect of ultrasound on the structural and textural properties of Al-Fe pillared clays in a concentrated medium," Catalysis Letters, vol. 130, no. 3-4, pp. 664-671, 2009.

[11] T. Mishra and K. M. Parida, "Effect of sulfate on the surface and catalytic properties of iron-chromium mixed oxide pillared clay," Journal of Colloid and Interface Science, vol. 301, no. 2, pp. 554-559, 2006.

[12] L. Huerta, A. Meyer, and E. Choren, "Synthesis, characterization and catalytic application for ethylbenzene dehydrogenation of an iron pillared clay," Microporous and Mesoporous Materials, vol. 57, no. 3, pp. 219-227, 2003.

[13] E. G. Rightor, M.-S. Tzou, and T. J. Pinnavaia, "Iron oxide pillared clay with large gallery height: synthesis and properties as a Fischer-Tropsch catalyst," Journal of Catalysis, vol. 130, no. 1, pp. 29-40, 1991.

[14] H. Auer and H. Hofmann, "Pillared clays: characterization of acidity and catalytic properties and comparison with some zeolites," Applied Catalysis A, vol. 97, no. 1, pp. 23-38, 1993.

[15] A. Pérez, M. A. Centeno, J. A. Odriozola, R. Molina, and S. Moreno, "The effect of ultrasound in the synthesis of clays used as catalysts in oxidation reactions," Catalysis Today, vol. 133-135, no. 1-4, pp. 526-529, 2008.

[16] F. Tomul and S. Balci, "Characterization of Al, Cr-pillared clays and CO oxidation," Applied Clay Science, vol. 43, no. 1, pp. 1320, 2009.

[17] M. Akçay, "The catalytic acylation of alcohols with acetic acid by using Lewis acid character pillared clays," Applied Catalysis A, vol. 269, no. 1-2, pp. 157-160, 2004.

[18] S. Letaïef, B. Casal, P. Aranda, M. A. Martín-Luengo, and E. Ruiz-Hitzky, "Fe-containing pillared clays as catalysts for phenol hydroxylation," Applied Clay Science, vol. 22, no. 6, pp. 263-277, 2003.

[19] J. Carriazo, E. Guélou, J. Barrault, J. M. Tatibouët, R. Molina, and S. Moreno, "Synthesis of pillared clays containing Al, AlFe or Al-Ce-Fe from a bentonite: characterization and catalytic activity," Catalysis Today, vol. 107-108, pp. 126-132, 2005.

[20] M. N. Timofeeva, S. T. Khankhasaeva, S. V. Badmaeva et al., "Synthesis, characterization and catalytic application for wet oxidation of phenol of iron-containing clays," Applied Catalysis B, vol. 59, no. 3-4, pp. 243-248, 2005.

[21] C. B. Molina, J. A. Casas, J. A. Zazo, and J. J. Rodríguez, "A comparison of Al-Fe and $\mathrm{Zr}$-Fe pillared clays for catalytic wet peroxide oxidation," Chemical Engineering Journal, vol. 118, no. 1-2, pp. 29-35, 2006.

[22] G. Mata, R. Trujillano, M. A. Vicente et al., "Chromiumsaponite clay catalysts: preparation, characterization and catalytic performance in propene oxidation," Applied Catalysis $A l$, vol. 327, no. 1, pp. 1-12, 2007.

[23] P. Yuan, F. Annabi-Bergaya, Q. Tao et al., "A combined study by XRD, FTIR, TG and HRTEM on the structure of delaminated Fe-intercalated/pillared clay," Journal of Colloid and Interface Science, vol. 324, no. 1-2, pp. 142-149, 2008.

[24] J. Zhou, P. Wu, Z. Dang et al., "Polymeric Fe/Zr pillared montmorillonite for the removal of $\mathrm{Cr}(\mathrm{VI})$ from aqueous solutions," Chemical Engineering Journal, vol. 162, no. 3, pp. 1035-1044, 2010.

[25] N. Maes, I. Heylen, P. Cool, and E. F. Vansant, "The relation between the synthesis of pillared clays and their resulting porosity," Applied Clay Science, vol. 12, no. 1-2, pp. 43-60, 1997.

[26] A. Rey, M. Faraldos, J. A. Casas, J. A. Zazo, A. Bahamonde, and J. J. Rodríguez, "Catalytic wet peroxide oxidation of phenol over Fe/AC catalysts: influence of iron precursor and activated carbon surface," Applied Catalysis B, vol. 86, no. 1-2, pp. 6977, 2009.

[27] E. G. Garrido-Ramírez, B. K. G. Theng, and M. L. Mora, "Clays and oxide minerals as catalysts and nanocatalysts in Fenton-like reactions-a review," Applied Clay Science, vol. 47, no. 3-4, pp. 182-192, 2010.

[28] H. Yalçın and Ö. Bozkaya, Alteration Mineralogy and Geochemistry of the Upper Cretaceous Volcanics around Hekimhan (Malatya), Central East Turkey: An Example for the SeawaterRock Interaction, A-Earth Sciences, Bulletin of Faculty of Engineering Cumhuriyet Üniversitesi, 2002.

[29] G. W. Brindley, "Quantitative X-Ray mineral analysis of clays," in Crystal Structures of Clay Minerals and Their XRay Identifications, G. W. Brindley and G. Brown, Eds., The Mineralogical Society, London, UK, 1980.

[30] F. Rouquerol, J. Rouquerol, and K. Sing, Adsorption by Powders and Porous Solids, Academic Press, London, UK, 1999.

[31] S. Lowell, J. E. Shields, M. A. Thomas, and M. Thommes, Characterization of Porous Solids and Powders: Surface Area Pore Size and Density, Kluwer Academic, Dodrecht, The Netherlands, 2004.

[32] J. D. Box, "Investigation of the Folin-Ciocalteau phenol reagent for the determination of polyphenolic substances in natural waters," Water Research, vol. 17, no. 5, pp. 511-525, 1983.

[33] M. Yurdakoç, M. Akçay, Y. Tonbul, F. Ok, and K. Yurdakoç, "Preparation and characterization of $\mathrm{Cr}$ - and Fe-pillared bentonites by using $\mathrm{CrCl} 3, \mathrm{FeCl} 3, \mathrm{Cr}(\mathrm{acac}) 3$ and $\mathrm{Fe}(\mathrm{acac}) 3$ as precursors," Microporous and Mesoporous Materials, vol. 111, no. 1-3, pp. 211-218, 2008.

[34] P. Yuan, H. He, F. Bergaya, D. Wu, Q. Zhou, and J. Zhu, "Synthesis and characterization of delaminated iron-pillared clay with meso-microporous structure," Microporous and Mesoporous Materials, vol. 88, no. 1-3, pp. 8-15, 2006.

[35] S. Balci and E. Gökçay, "Pore structure and surface acidity evaluation of Fe-PILCs," Turkish Journal of Chemistry, vol. 33, no. 6, pp. 843-856, 2009.

[36] S. Balci and E. Gökçay, "Effects of drying methods and calcination temperatures on the physical properties of iron intercalated clays," Materials Chemistry and Physics, vol. 76, no. 1, pp. 46-51, 2002.

[37] A. Moronta, T. Oberto, G. Carruyo et al., "Isomerization of 1-butene catalyzed by ion-exchanged, pillared and ionexchanged/pillared clays," Applied Catalysis A, vol. 334, no. 12, pp. 173-178, 2008.

[38] F. Tomul, "Synthesis, characterisation and adsorption properties of Fe/Cr-pillared bentonites," Industrial \& Engineering Chemistry Research, vol. 50, no. 12, pp. 7228-7240, 2011.

[39] A. Gil and L. M. Gandía, "Microstructure and quantitative estimation of the micropore-size distribution of an aluminapillared clay from nitrogen adsorption at $77 \mathrm{~K}$ and carbon 
dioxide adsorption at 273K," Chemical Engineering Science, vol. 58, no. 14, pp. 3059-3075, 2003.

[40] A. Gil, S. A. Korili, R. Trujillano, and M. A. Vicente, "A review on characterization of pillared clays by specific techniques," Applied Clay Science, vol. 53, pp. 97-105, 2010.

[41] B. Smith, Infrared Spectral Interpretation A Systematic Approch, CRC Press, New York, NY, USA, 1998.

[42] J. Madejová, "FTIR techniques in clay mineral studies," Vibrational Spectroscopy, vol. 31, no. 1, pp. 1-10, 2003.

[43] S. Todorova and B. L. Su, "Propane as alkylating agent for benzene alkylation on bimetal Ga and Pt modified H-ZSM5 catalysts: FTIR study of effect of pre-treatment conditions and the benzene adsorption," Journal of Molecular Catalysis A, vol. 201, no. 1-2, pp. 223-235, 2003.

[44] S. Zuo and R. Zhou, "Al-pillared clays supported rare earths and palladium catalysts for deep oxidation of low concentration of benzene," Applied Surface Science, vol. 253, no. 5, pp. 2508-2514, 2006.

[45] M. Kurian and S. Sugunan, "Characterisation of the acidbase properties of pillared montmorillonites," Microporous and Mesoporous Materials, vol. 83, no. 1-3, pp. 25-34, 2005.

[46] P. Cañizares, J. L. Valverde, M. R. Sun Kou, and C. B. Molina, "Synthesis and characterization of PILCs with single and mixed oxide pillars prepared from two different bentonites. A comparative study," Microporous and Mesoporous Materials, vol. 29, no. 3, pp. 267-281, 1999.

[47] J. G. Carriazo, M. A. Centeno, J. A. Odriozola, S. Moreno, and R. Molina, "Effect of Fe and $\mathrm{Ce}$ on Al-pillared bentonite and their performance in catalytic oxidation reactions," Applied Catalysis A, vol. 317, no. 1, pp. 120-128, 2007.

[48] N. Sanabria, A. Álvarez, R. Molina, and S. Moreno, "Synthesis of pillared bentonite starting from the Al-Fe polymeric precursor in solid state, and its catalytic evaluation in the phenol oxidation reaction," Catalysis Today, vol. 133-135, no. 1-4, pp. 530-533, 2008.

[49] C. Catrinescu, C. Teodosiu, M. Macoveanu, J. Miehe-Brendlé, and R. Le Dred, "Catalytic wet peroxide oxidation of phenol over Fe-exchanged pillared beidellite," Water Research, vol. 37, no. 5, pp. 1154-1160, 2003. 

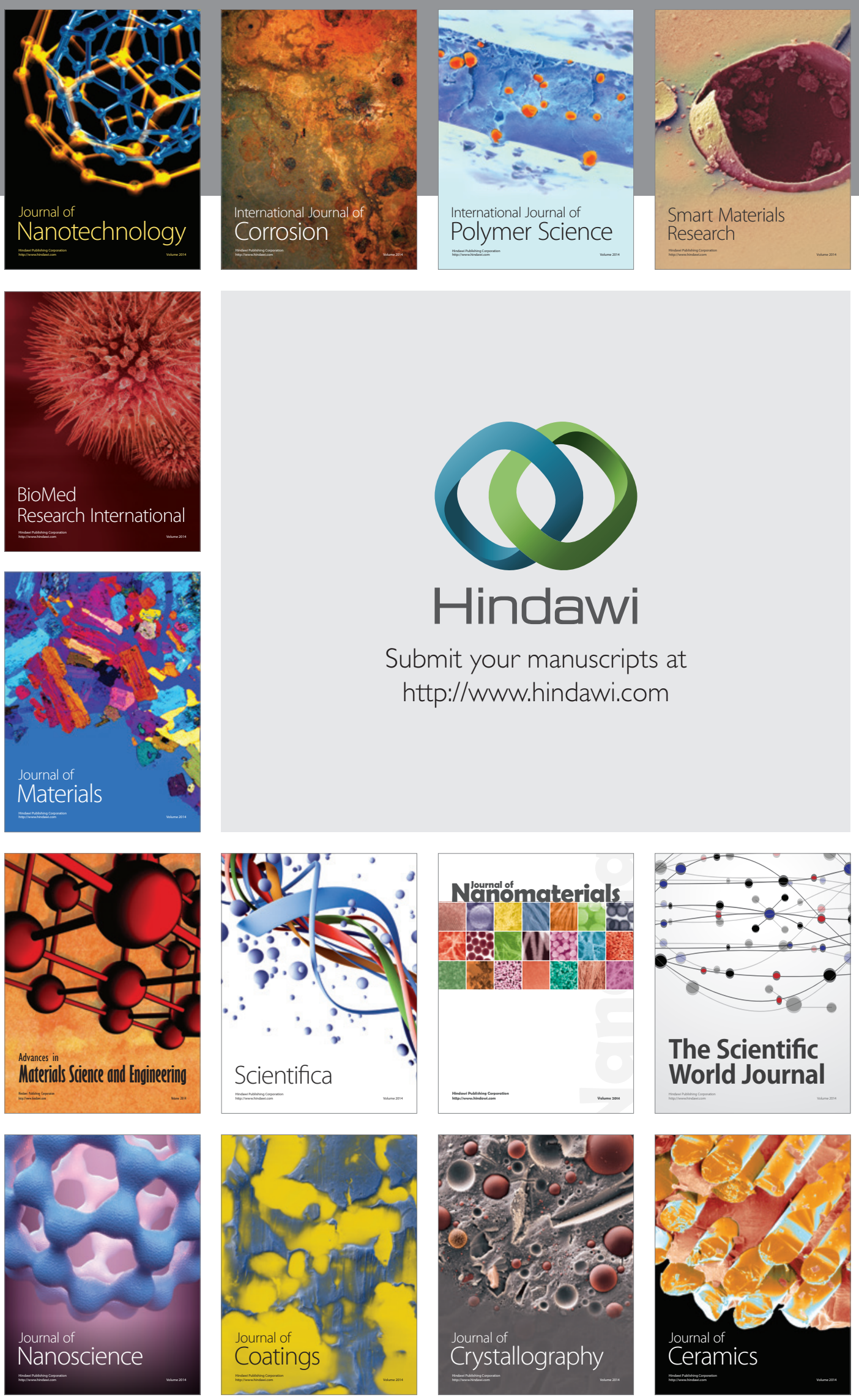

The Scientific World Journal

Submit your manuscripts at

http://www.hindawi.com

\section{World Journal}

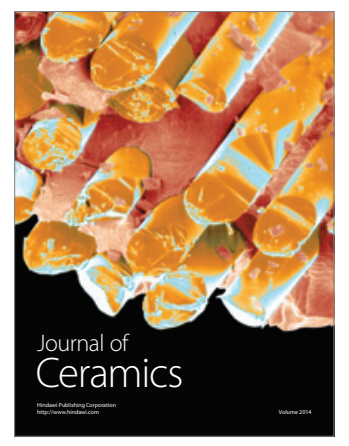

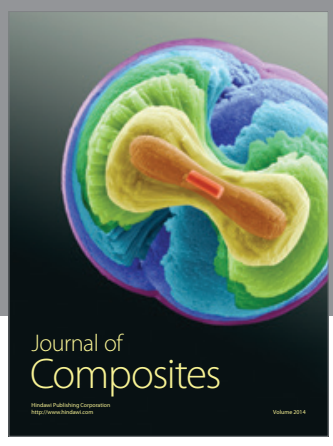
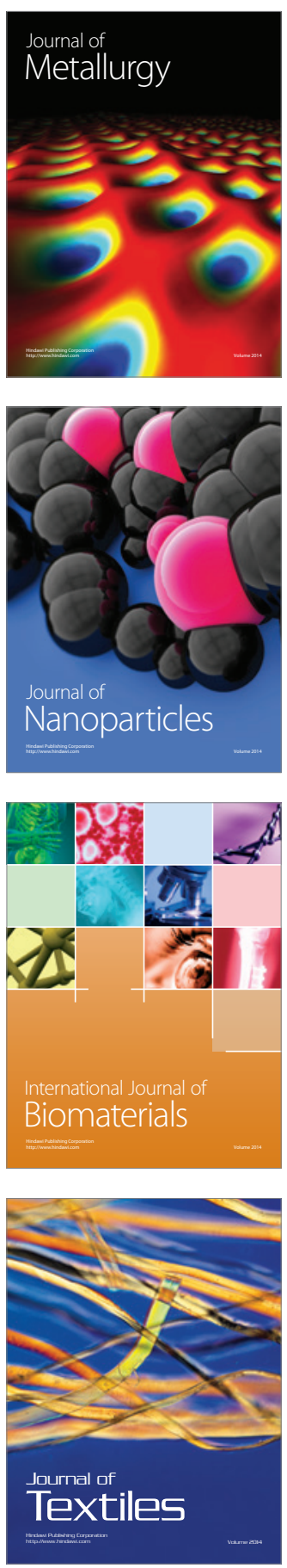